\title{
Improvement of cosmeceutical properties in rice by-products by solid state fermentation with Aspergillus oryzae and effects of different extracting conditions
}

\author{
*Abd Ghani, A., Abd Rashid, N.Y., Jamaluddin, A., Abd Razak, D.L. and \\ Abdul Manan, M. \\ Enzyme and Fermentation Technology Programme, Food Science and Technology Research Centre, \\ Malaysian Agricultural Research and Development Institute (MARDI), 43400 Serdang, Selangor, Malaysia
}

\begin{abstract}
Article history:
Received: 15 April 2020

Received in revised form: 10

September 2020

Accepted: 25 January 2021

Available Online: 31 January 2021
\end{abstract}

Keywords:

Aspergillus fungi,

Cosmeceutical,

Extraction,

Rice bran,

Rice by-products,

Solid-state fermentation

DOI:

https://doi.org/10.26656/fr.2017.5(S1).025

\begin{abstract}
Rice milling generates a lot of rice by-products and they are commonly used as an animal feed ingredient. However, they have high cosmeceutical values, attributed to their high content of bioactive compounds. In the present study, rice by-products (broken rice and rice bran) were subjected to solid state fermentation (SSF) using Aspergillus oryzae at $30^{\circ}$ $\mathrm{C}$ for 12 days and their cosmeceutical potentials were then evaluated. Different extraction conditions such as the type of solvent (water, 50\% ethanol) and extraction temperature $\left(30^{\circ} \mathrm{C}, 40^{\circ} \mathrm{C}\right)$ were also optimized using a one-factor-one-time approach. Through tyrosinase inhibition assay, it was observed that SSF has improved the anti-pigmentation effect of broken rice and rice bran 7.4-fold and 11.2-fold in comparison to their unfermented substrate, respectively. SSF has also improved the anti-ageing effect of broken rice and offered 6.6-fold of improvement in fermented rice bran. In extraction optimization studies, a stronger anti-ageing effect was observed in the water extract of both fermented substrates extracted at $40^{\circ} \mathrm{C}$ while the anti-pigmentation effect is stronger on $50 \%$ ethanol extract in fermented rice bran. Most phenolic acids that are commonly related to cosmeceutical purposes were detected in the extracts of both fermented substrates while most of the organic acids were detected in the water extract. Our study suggests that SSF using $A$. oryzae could improve the cosmeceutical activities of rice byproducts, and both water and $50 \%$ ethanol extracts have high potential to be developed as cosmeceutical bio-ingredients.
\end{abstract}

\section{Introduction}

Recent trends in cosmeceutical development are focussing on natural and non-irritating ingredients to improve the appearance of skin (Brandt et al., 2011). A lot of cosmeceutical ingredients are now developed from agricultural by-products due to their abundance, naturalness and low cost. Malaysia is one of the world's rice-producing countries. In 2015, 400,906 tonnes of paddy was milled but only about $60.7 \%$ was sold as graded rice, while the rest became by-products including broken rice and rice bran (Ministry of Agriculture, 2017). Generally, these residues are only utilized as animal feed ingredient or discarded as waste. While broken rice and rice bran have been recognized as an excellent source of nutrients and bioactive compounds, it is of great benefit to diversify their utilization and generate new high value-added products.

Over the last few decades, SSF has been extensively studied as a promising tool that can valorise the agricultural by-products into high value-added products. During the fermentation process, enzymes such as cellulases, xylanase, pectinase and esterases are produced by the microorganisms and led to the generation of bioactive components that can contribute to the bioactivities of the fermented by-products. Few reports have demonstrated the potential of SSF in improving the cosmeceutical activities of certain agricultural by-products in terms of tyrosinase and elastase inhibition activities and also antioxidant activities. Our previous studies have shown that fermentation of broken rice with Aspergillus niger and Rhizopus oligosporus (Abd. Razak, Abd. Rashid, Jamaluddin et al., 2019) and fermentation of rice bran with Amylomyces rouxii (Abd Ghani et al., 2018) have significantly improved their cosmeceutical properties.

However, research on the cosmeceutical activities of 
fermented rice by-products with $A$. oryzae is yet to be done. In addition, research on the effects of extraction condition on the cosmeceutical properties of fermented products is scarce. In fact, efficient downstream processing is crucial in the SSF system. For the development of fermented rice by-products as a cosmetic ingredient, the extraction condition is important for maximum efficacy. Different extraction condition such as extraction solvent and extraction temperature may affect the extraction efficiency of bioactive compounds and consequently affecting the cosmeceutical properties of fermented rice by-products.

Therefore, in this study, the activities of cosmeceutical properties of rice by-products including broken rice and rice bran in SSF by A. oryzae in terms of tyrosinase and elastase inhibition activity were investigated. Then, the influences of different extraction solvent and extraction temperature on the cosmeceutical properties, as well as their bioactive compounds were also investigated. To the best of our knowledge, this is the first report on the effects of different extraction conditions on the cosmeceutical properties of A. oryzae fermented broken rice and rice bran.

\section{Materials and methods}

\subsection{Preparation of inoculums and substrate}

The fungus $A$. oryzae F0017 was obtained from MARDI's Collection of Functional Food Cultures (CFFC), Selangor, Malaysia while broken rice and rice bran were obtained from Padiberas Nasional Berhad (Bernas, Selangor, Malaysia). The culture was grown on potato dextrose agar (PDA) and maintained at $30^{\circ} \mathrm{C}$. The inoculum was prepared from 5 days old slant by suspending the fungal spores in Tween $80(0.01 \%)$ and adjusted to a concentration of $1 \times 10^{6}$ spores $/ \mathrm{mL}$. Prior use, broken rice and rice bran were washed thoroughly and dried at $40^{\circ} \mathrm{C}$ for $24 \mathrm{hrs}$.

\subsection{Solid state fermentation}

A total of $30 \mathrm{~g}$ of rice bran and $90 \mathrm{~g}$ of broken rice were added to separate Erlenmeyer flasks and autoclaved at $121^{\circ} \mathrm{C}$ for 15 mins. Then, their moisture content was adjusted to $50 \%$ with sterilized distilled water. Next, $1 \%$ $(\mathrm{v} / \mathrm{w})$ of fungal spores was inoculated into the substrates, mixed properly and incubated at $30^{\circ} \mathrm{C}$ for 12 days. Unfermented rice bran and broken rice were used as control. The subsamples were then harvested and dried at $50^{\circ} \mathrm{C}$ for $24 \mathrm{hrs}$ in the oven before they were extracted with distilled water and filtered through Whatman No. 1 filter paper.

\subsection{Optimization of extraction}

A total of $30 \mathrm{~g}$ of rice bran and $90 \mathrm{~g}$ of broken rice were added to separate beakers and autoclaved at $121^{\circ} \mathrm{C}$ for 15 mins. Then, their moisture content was adjusted to $50 \%$ with sterilized distilled water. Approximately, 1\% sterile molasses and $1 \%$ sterile soybean waste were also added into the beaker as a nutrient supplement to the rice bran and broken rice, respectively. Next, $1 \%(\mathrm{v} / \mathrm{w})$ of fungal spores was inoculated into the substrates, mixed properly and transferred into sterile Petri dish. They were then incubated at $30^{\circ} \mathrm{C}$ for 12 days.

After SSF, all samples were subjected to dry in the oven at $50^{\circ} \mathrm{C}$ for $24 \mathrm{hrs}$. Then they were mixed with the extraction solvent, either water or $50 \%$ ethanol $(1: 5 \mathrm{w} / \mathrm{v})$ and shaken on an incubator shaker at $150 \mathrm{rpm}$ for $2 \mathrm{hrs}$ at either $30^{\circ} \mathrm{C}$ or $40^{\circ} \mathrm{C}$. Next, the samples were centrifuged at $10000 \mathrm{rpm}$ for $5 \mathrm{mins}$ and then filtered using membrane filter (Whatman, $0.22 \mu \mathrm{m}$ ). Prior to analysis, the extracts were stored at $-20^{\circ} \mathrm{C}$.

\subsection{Tyrosinase inhibition activity}

Tyrosinase inhibition activity was performed using the dopachrome method using 1-3,4dihydroxyphenylalanine (L- DOPA) as the substrate according to the method by Alam et al. (2012) with minor modifications. Approximately, $40 \mu \mathrm{L}$ of the test sample solution were mixed with $40 \mu \mathrm{L}$ of mushroom tyrosinase $(31 \mathrm{U} / \mathrm{mL})$ and $80 \mu \mathrm{L}$ of $0.1 \mathrm{M}$ phosphate buffer ( $\mathrm{pH} 6.8$ ) in a 96-well plate. Then, the mixture was incubated at $25^{\circ} \mathrm{C}$ for 5 mins. Then, $40 \mu \mathrm{L}$ of $10 \mathrm{mM} \mathrm{L}$ DOPA solution was added into the mixture and incubated again for 10 mins. Next, the absorbance was measured at $475 \mathrm{~nm}$ using the microplate reader (Versamax). Each sample was accompanied by a blank containing all components except L-DOPA. Kojic acid was used as positive controls.

\subsection{Elastase inhibition activity}

Anti-wrinkle potential of samples was evaluated by measuring their elastase inhibition activity using Elastase Assay Kit (EnzChek, USA). An aliquot of sample (50 $\mu \mathrm{L})$ was added to $100 \mu \mathrm{L}$ of $0.5 \mathrm{U} / \mathrm{mL}$ porcine pancreatic elastase and incubated in the dark at room temperature for 15 mins. Then, $50 \mu \mathrm{L}$ of $\mathrm{DQ}^{\mathrm{TM}}$ elastin working solution $(25 \mu \mathrm{g} / \mathrm{mL})$ was added into the mixture followed by incubation in the dark for 30 mins. Absorbance at 505/515 nm (Ex/Em) was measured using a fluorescent microplate reader. N-methoxy (Nmethoxysuccinyl-Ala-Ala-Pro-Val-chloromethyl ketone) was used as a reference inhibitor.

Tyrosinase and elastase inhibition activities were 
calculated using the following equation:

$$
\% \text { inhibition }=\{[(\mathrm{A}-\mathrm{B})-(\mathrm{C}-\mathrm{D})] /(\mathrm{A}-\mathrm{B})\} \times 100
$$

Where $\mathrm{A}=$ absorbance of the blank solution with enzyme, $\mathrm{B}=$ absorbance of the blank solution without enzyme, $\mathrm{C}=$ absorbance of sample solution with enzyme and $\mathrm{D}=$ absorbance of sample solution without enzyme

\subsection{Phenolic acid composition}

The determination of phenolic acids composition was carried out by using High Performance Liquid System (HPLC) Alliance (Waters 2695) equipped with a photo-diode array detector (Waters 2996). The phenolic acids in the sample were separated on a reversed-phase analytical column (150 mm x $4.6 \mathrm{~mm}$ x Bridge C18, 3.5 $\mu \mathrm{m}$, Waters). The separation carried out in mobile phase consisted of $0.1 \%$ formic acid (A) and methanol (B) with the flow rate set at $0.7 \mathrm{~mL} / \mathrm{min}$. The detector was set at $270 \mathrm{~nm}$ and $325 \mathrm{~nm}$ and peak identification were performed by comparing the retention times to the standard phenolic acids. Quantification of phenolic acids was performed using the calibration curves obtained by injecting known amounts of standard compounds.

\subsection{Organic acid composition}

The quantification of organic acids was accomplished using Waters HPLC. Organic acids in the sample were separated on a $250 \mathrm{~mm}$ x $4.6 \mathrm{~mm}$, Extrasil ODS $5 \mu \mathrm{m}$ column. The separation of organic acids was conducted in isocratic conditions at $30^{\circ} \mathrm{C}$, using $50 \mathrm{mM}$ phosphate solution ( $\mathrm{pH} \mathrm{2.8)}$ as the mobile phase with the flow rate of $0.7 \mathrm{~mL} / \mathrm{min}$. Peak identification was made by comparing retention times and UV spectra at $210 \mathrm{~nm}$ and $245 \mathrm{~nm}$ with authentic compounds. Quantification was made using calibration curves obtained by injecting known amounts of pure compounds as external standards.

\subsection{Statistical analysis}

Mean values and standard deviations were calculated from the data obtained from triplicate experiments. In determining the significance of the data, one-way analysis of variance (ANOVA) was conducted using Minitab Statistical Software (Version 18). Differences between means with a p-value of $<0.05$ were considered statistically significant.

\section{Results and discussion}

3.1 Improvement of cosmeceutical properties in rice byproducts by SSF

The cosmeceutical properties of fermented and unfermented rice by-products were determined by performing tyrosinase and elastase inhibition assays. Tyrosinase is an important enzyme that involves in melanin biosynthesis. It converts tyrosine to dihydroxyphenylalanine (DOPA) and then oxidizes it to dopaquinone. Dopaquinone then forms melanin through a series of reactions (Zaidi et al., 2014). Meanwhile, elastase is a metalloproteinase enzyme that degrades elastin which provides firmness and elasticity to human skin; hence tyrosinase and elastase activity inhibition could be used as a method to measure the protection of the skin against pigmentation and ageing, respectively.

Figure 1 presents the inhibition activity of both enzymes in unfermented and fermented broken rice and rice bran. SSF by $A$. oryzae has significantly improved the tyrosinase inhibition activity of broken rice (68.8\%) and rice bran (18.9\%), 7.4-fold and 11.2-fold in comparison to their unfermented substrate, respectively. Meanwhile, the strongest inhibition of elastase was observed in fermented rice bran $(60.5 \%)$, a 6.6 -fold significantly higher than the unfermented rice bran. Interestingly, SSF has improved the elastase inhibition activity in fermented broken rice $(17.9 \%)$ where there was no activity of elastase inhibition in the unfermented broken rice observed. This indicates that SSF played significant roles in improving anti-pigmentation and antiageing properties in the rice by-products.

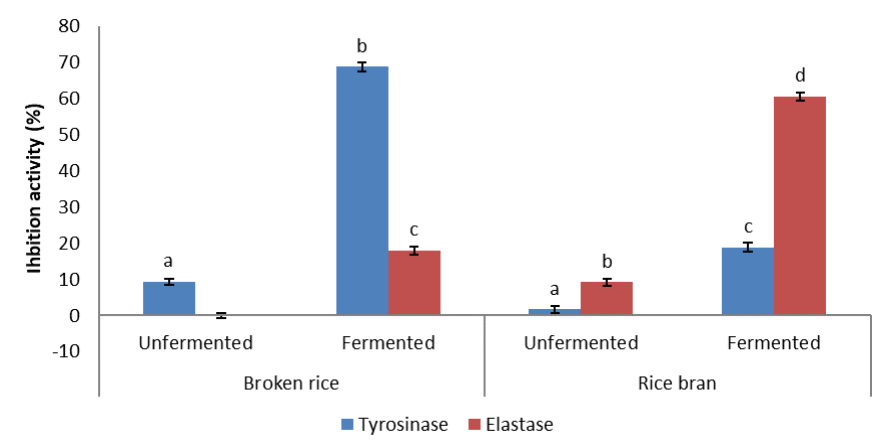

Figure 1. Tyrosinase and elastase inhibition activity of unfermented and fermented broken rice and rice bran. Bars with the same letter in each category are not significantly different $(\mathrm{p}>0.05)$

SSF is a complex biochemical process that produces various hydrolyzing enzymes like a-amylase, bglucosidase, xylanase, and esterases which may be associated with the release of water-soluble phenolic content from the insoluble bound form of broken rice and rice bran (Dey and Kuhad, 2014). Along the process, some unknown biochemical pathways may be involved in increasing their various functional properties including cosmeceutical properties. A study by Abd. Razak, Jamaluddin, Abd. Rashid et al. (2019) previously also showed the potential of SSF by A. oryzae in improving tyrosinase and elastase inhibition activity in other types of rice by-product, which is brewer's rice, up to 6- and 11-fold, respectively. The enhancement of bioactivities 
in rice by-products was varied for each microorganism used. Jamaluddin et al. (2014) has reported the enhancement of elastase inhibition activity of rice bran in SSF by Monascus purpureus and Aspergillus niger about 2.5-fold and 1.4-fold, respectively.

\subsection{Effect of extraction temperature and solvent on tyrosinase inhibition activity}

Various extraction conditions such as type of solvent, solvent to solid ratio, extraction temperature, time, and $\mathrm{pH}$ could affect the extraction efficiency of plant materials and consequently may influence their bioactivities. In this study, different solvent type and extraction temperature were optimized using a one-factor -one-time approach to determine their effect on the cosmeceutical activities of fermented rice by-products. Figure 2 shows the tyrosinase inhibition activity of fermented broken rice and rice bran, extracted at different temperature $\left(30^{\circ} \mathrm{C}\right.$ and $\left.40^{\circ} \mathrm{C}\right)$ with different solvent (water and $50 \%$ ethanol).

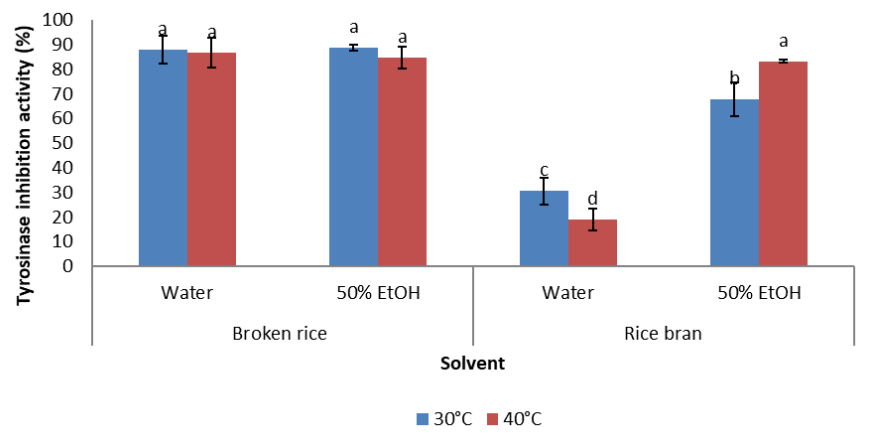

Figure 2. Tyrosinase inhibition activity of extracts from different extraction condition. Bars with the same letter in each category are not significantly different $(p>0.05)$

In rice bran, the type of extraction solvent affected the tyrosinase inhibition activity substantially. Higher tyrosinase inhibition activity was significantly observed in $50 \%$ ethanol extract in comparison to the water extract. On the contrary, there was no significant difference between water extract and $50 \%$ ethanol extract in broken rice in terms of tyrosinase inhibition activity. Comparing the two substrates, broken rice was the most active in inhibiting tyrosinase. Similarly, the extraction temperature did not significantly affect the tyrosinase inhibition activity of fermented broken rice. Contrarily in rice bran, 50\% ethanol extract exhibited significantly higher tyrosinase inhibition activity when extracted at $40^{\circ} \mathrm{C}(83.3 \%)$ while the water extract exhibited significantly lower tyrosinase inhibition activity $(19.1 \%)$ at the same temperature. This indicates that both the solvent type and extraction temperature played significant roles in achieving the desired cosmeceutical characteristics of the extract, especially in fermented rice bran. The selection of an appropriate extraction method and temperature is among the key steps to consider before proceeding to cosmeceutical formulation development (Ciganovic et al., 2019).

Many previous studies have found that aqueous mixtures of organic solvents will greatly increase the tyrosinase inhibition activity and antioxidants efficiency of most plant products (Venkatesan et al., 2019). Compared to water alone, the fermented methanol and ethanol extract of Magnolia officinalis by Aspergillus niger exhibited higher anti-tyrosinase activity, total phenolic content, and antioxidant activity ( $\mathrm{Wu}$ et al., 2018). Wang et al. (2016) have also reported that the $50 \%$ ethanol extract of Bifidobacterium bifidumfermented Chinese Herbs including walnut, Moutan Cortex Radicis, and asparagus root exhibited the highest tyrosinase inhibition activity among all extracts.

\subsection{Effect of extraction temperature and solvent on elastase inhibition activity}

Enzymatic activity of elastase promotes skin ageing with symptoms such as wrinkling and sagging due to the loss of flexibility and elasticity in the skin. Therefore, there is growing interest in the development of safe and effective elastase inhibitors from the natural source. As depicted in Figure 3, the elastase inhibition activity of water extract of both fermented broken rice and rice bran extracted at $40^{\circ} \mathrm{C}$ were significantly higher, with a value of $75 \%$ for broken rice and $90.5 \%$ for rice bran compared to the $50 \%$ ethanol extract (60.9\% and 53.6\%), respectively. This is consistent with a study by Song et al. (2019) who also found that water extract of Cinnamomum yabunikkei H.Ohba leaf has higher elastase inhibition activity than the ethanol extract. Other findings by Cho et al. (2011) also confirmed that elastase inhibition was higher in water extract of Lycium chinense.

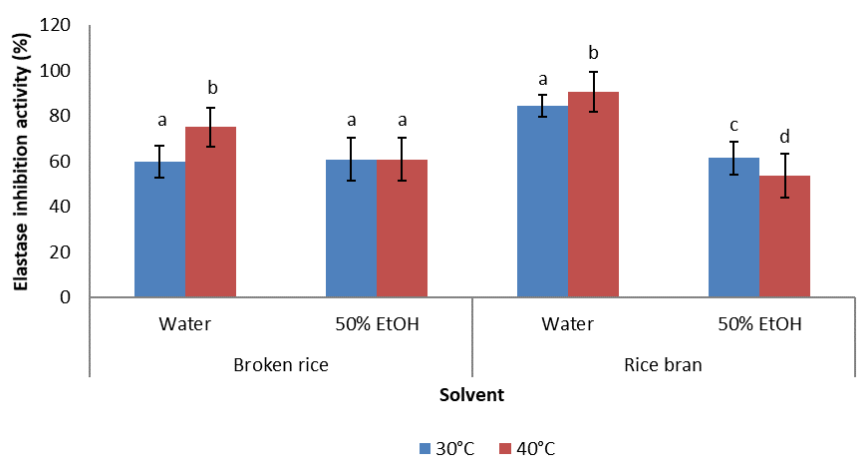

Figure 3. Elastase inhibition activity of extracts from different extraction condition. Bars with the same letter in each category are not significantly different $(\mathrm{p}>0.05)$

Figure 3 also shows that $40^{\circ} \mathrm{C}$ was the most favourable extraction temperature for higher elastase inhibition activity for both water extract of broken rice and rice bran. On the other hand, in 50\% ethanol extract of rice bran, significantly higher elastase activity was 
found when extracted at $30^{\circ} \mathrm{C}$ while elastase inhibition activity was not affected significantly by extraction temperature in $50 \%$ ethanol extract of broken rice. According to Shi et al. (2003), theoretically, under high temperatures, plant tissues were softened and the weak interactions affected the cell membranes. As a result, phenolic compounds that were contributed to the elastase inhibition activity may be easily extracted into the solvent.

\subsection{Effect of extraction temperature and solvent on phenolic acid content}

Table 1 shows the phenolic acid content in fermented broken rice and rice bran. In fermented broken rice, only gallic, protocatechuic, vanillic, syringic, and benzoic acid were identified. The highest phenolic acid content found was benzoic acid which was extracted in the water at $40^{\circ} \mathrm{C}(22 \mu \mathrm{g} / \mathrm{mL})$. Other phenolic acids such as vanillic and syringic acid were found in significantly higher content in 50\% ethanol extract except for gallic acid where there was no significant difference amount of it in both extracts. Caffeic, ferulic, and p-coumaric were not identified with any solvent meanwhile protocatechuic acid was only detected with water. The presence of gallic acid in fermented broken rice suggested that this compound has contributed to the high tyrosinase inhibition activity of the extract as has been reported by Su et al. (2013), gallic acid inhibited tyrosinase and decreased melanin synthesis. Kumar et al. (2013) has also suggested gallic acid as an effective de-pigmenting or skin lightening cosmeceutical agent. It was also observed that extraction temperature did not show a significant difference on the most phenolic acid content except vanillic acid which was found significantly higher when extracted at $30^{\circ} \mathrm{C}$ using water and benzoic acid which was found significantly higher when extracted at $40^{\circ} \mathrm{C}$ using water.

In rice bran, only caffeic, ferulic, protocatechuic, $\mathrm{p}$ - coumaric and benzoic acid were identified. The highest content of phenolic acid in fermented rice bran was observed in $50 \%$ ethanol extract which was p-coumaric acid $(8.18 \mu \mathrm{g} / \mathrm{mL})$ extracted at $30^{\circ} \mathrm{C}$, but the amount was not significantly different with extraction temperature of $40^{\circ} \mathrm{C}(7.88 \mu \mathrm{g} / \mathrm{mL})$. Similarly, higher content of caffeic and protocatechuic acid was significantly found in $50 \%$ ethanol extract of rice bran compared to its water extract. On the other hand, benzoic acid extracted at $40^{\circ} \mathrm{C}$ showed significantly higher concentration with water extract.

The presence of p-coumaric acid in both rice bran extracts was interesting as this compound has been reported to contain anti-tyrosinase, anti-inflammatory, anti-collagenase and anti-microbial properties, thus increasing the cosmeceutical values of the fermented rice bran (Taofiq et al., 2016). In addition, the ferulic acid and caffeic acid also have been reported to display the tyrosinase inhibition activity (Thangboonjit et al., 2014). A lot of studies have reported that alcohol/water solution exerts a better influence on the extractability of phenolic compounds compared to the mono-component solvents. López-Perea et al. (2019) also found that the addition of water to the solvents has increased the extraction efficiency of bioactive compounds of wheat bran and barley husk.

Temperature has not significantly affected most of the phenolic acid content in both extracts in rice bran. However, extraction at $40^{\circ} \mathrm{C}$ was found to be significantly favourable in producing higher content of caffeic, protocatechuic, p-coumaric, and benzoic acid. Dey and Kuhad (2014) also observed the higher content of phenolic acids from Rizhopus oryzae-fermented wheat grain when extracted at $40^{\circ} \mathrm{C}$. According to Spigno et al. (2007), mild heating can soften plant tissues and weaken the cell wall integrity and so favoured the release of bound phenolic compounds.

Table 1. Phenolic acids content of fermented broken rice and rice bran extracts

\begin{tabular}{|c|c|c|c|c|c|c|c|c|}
\hline \multirow{4}{*}{ Phenolic acid } & \multicolumn{8}{|c|}{ Compound content $(\mu \mathrm{g} / \mathrm{mL}) *$} \\
\hline & \multicolumn{4}{|c|}{ Fermented broken rice } & \multicolumn{4}{|c|}{ Fermented rice bran } \\
\hline & \multicolumn{2}{|c|}{ Water } & \multicolumn{2}{|c|}{$50 \% \mathrm{EtOH}$} & \multicolumn{2}{|c|}{ Water } & \multicolumn{2}{|c|}{$50 \% \mathrm{EtOH}$} \\
\hline & $30^{\circ} \mathrm{C}$ & $40^{\circ} \mathrm{C}$ & $30^{\circ} \mathrm{C}$ & $40^{\circ} \mathrm{C}$ & $30^{\circ} \mathrm{C}$ & $40^{\circ} \mathrm{C}$ & $30^{\circ} \mathrm{C}$ & $40^{\circ} \mathrm{C}$ \\
\hline Gallic & $3.0 \pm 0.02^{\mathrm{a}}$ & $2.8 \pm 0.01^{\mathrm{a}}$ & $2.29 \pm 0.00^{\mathrm{a}}$ & $2.5 \pm 0.01^{\mathrm{a}}$ & nd & nd & nd & nd \\
\hline Caffeic & nd & nd & nd & nd & $0.59 \pm 0.02^{\mathrm{a}}$ & $1.0 \pm 0.01^{\mathrm{b}}$ & $2.74 \pm 0.34^{\mathrm{c}}$ & $2.86 \pm 0.33^{\mathrm{c}}$ \\
\hline Ferulic & nd & nd & nd & nd & $1.69 \pm 0.07^{\mathrm{a}}$ & $2.02 \pm 0.67^{\mathrm{a}}$ & $1.30 \pm 0.01^{\mathrm{a}}$ & $1.79 \pm 0.09^{\mathrm{a}}$ \\
\hline protocatechuic & $6.97^{\mathrm{a}}$ & $6.03^{\mathrm{a}}$ & nd & nd & $3.14 \pm 0.16^{\mathrm{a}}$ & $4.44 \pm 0.36^{\mathrm{b}}$ & $5.12 \pm 0.99^{\mathrm{c}}$ & $7.43 \pm 1.98^{\mathrm{d}}$ \\
\hline p-coumaric & nd & nd & nd & nd & $4.54 \pm 1.04^{\mathrm{a}}$ & $5.42 \pm 1.22^{\mathrm{b}}$ & $8.18 \pm 1.26^{\mathrm{c}}$ & $7.88 \pm 1.67^{\mathrm{c}}$ \\
\hline Vanillic & $8.52 \pm 2.01^{\mathrm{a}}$ & $6.81 \pm 1.78^{\mathrm{b}}$ & $11.64 \pm 2.82^{\mathrm{c}}$ & $11.85 \pm 3.08^{\mathrm{c}}$ & nd & nd & nd & nd \\
\hline Syringic & $1.74 \pm 0.08^{\mathrm{a}}$ & $1.30 \pm 0.05^{\mathrm{a}}$ & $2.23 \pm 0.79^{\mathrm{b}}$ & $2.09 \pm 0.26^{\mathrm{b}}$ & nd & nd & nd & nd \\
\hline Benzoic & $17.71 \pm 2.09^{\mathrm{a}}$ & $22 \pm 3.11^{\mathrm{b}}$ & $1.38 \pm 0.06^{\mathrm{c}}$ & $2.96 \pm 0.71^{\mathrm{d}}$ & $1.08 \pm 0.01^{\mathrm{a}}$ & $6.15 \pm 0.18^{b}$ & $1.38 \pm 0.03^{\mathrm{a}}$ & $1.41 \pm .02^{\mathrm{a}}$ \\
\hline
\end{tabular}

Values are expressed as mean \pm SD. Values with the same superscript within the row are not significantly different $(p>0.05)$. nd $=$ not detected. 
Comparing both substrates, broken rice contained higher overall phenolic acids with concentrations ranging from $1.3 \mu \mathrm{g}-22 \mu \mathrm{g} / \mathrm{mL}$ while only $1-8.18 \mu \mathrm{g} / \mathrm{mL}$ in rice bran. The variation of phenolic acid compositions in fermented plant products was highly affected by the extraction solvent due to the different polarity. The phenolic acid content in this study was lower than reported by Schmidt et al. (2014) who studied Rizhopus oryzae fermented rice bran extracted with methanol.

\subsection{Effect of extraction temperature and solvent on organic acid content}

For a better understanding of the cosmeceutical properties of fermented rice-by-products extracts, we analyzed the organic acid content of fermented extracts using HPLC. The ability of Aspergillus species to transform a wide range of carbohydrates into organic acids is well known. Through HPLC, a total of four types of organic acid (citric, kojic, ascorbic, lactic) were identified in fermented broken rice water extract and only three types (citric, kojic, lactic) were identified in fermented rice bran, and the content of these organic acids was listed in Table 2. It was observed that citric acid was the major compound identified in broken rice water extract $(136.88 \mathrm{mg} / \mathrm{mL})$. Similarly, other organic acids such as kojic, ascorbic, and lactic acid were only presented in the water extract of broken rice. The temperature did not give significant effect on the amount of most organic acids in fermented broken rice except citric acid.

The highest organic acid content in rice bran was kojic acid extracted at $40^{\circ} \mathrm{C}$ in water $(119.01 \mathrm{mg} / \mathrm{mL})$ but that was not significantly different from extraction at $30^{\circ} \mathrm{C}(116.4 \mathrm{mg} / \mathrm{mL})$. However, no kojic acid was present in $50 \%$ ethanol extract. Similarly, lactic acid was only detected in the water extract of fermented rice bran. On the other hand, ascorbic acid was not identified with any solvent in fermented rice bran. The presence of citric acid, kojic acid, ascorbic acid and lactic acid in the fermented samples increased their potentials as cosmeceutical agents. Citric acid is a type of $\beta$-hydroxy acid that is widely used as an antioxidant in the cosmetic formulation (Kornhauser et al., 2012). Kojic acid prevents the generating of melanin by inhibiting the activities of tyrosinase, thus it is widely used as skin whitening, skin lightener or depigmenting agent in cosmetic formulations and other applications such as pharmaceuticals (Saeedi et al., 2019). Besides, ascorbic acid is also commonly used as a tyrosinase inhibitor because it can affect the chemical reduction of dopaquinone, thereby avoiding the formation of dopachrome and melanin by the subsequent reduction of dopaquinone to L-DOPA (Cui et al., 2018). The presence of ascorbic acid in fermented broken rice suggests its high tyrosinase inhibition activity of the extract. Other important organic acids such as lactic acid also can act as skin anti-ageing tool by reducing the appearance of fine lines and wrinkles and can help to promote collagen production, which then will firm the skin. Lactic acid also plays a major role in lightening age spots by the repression of the formation of tyrosine (Alsaheb et al., 2015).

However, it is important to note that the overall cosmeceutical activity in an extract is not necessarily indicated by the type or the quantity of individual bioactive compounds in the extract. Their combined effect either synergistic or antagonistic may have played a vital role in enhancing their potential as a functional ingredient in cosmeceutical products.

\section{Conclusion}

The SSF of rice by-products by $A$. oryzae is a good valorization technique that produces valuable bioactive compounds with promising cosmeceutical activities. Study on the optimization of extraction conditions has further improved their cosmeceutical properties. Both the solvent type and extraction temperature played significant roles in achieving the desired cosmeceutical characteristics of the extract. However, it is difficult to determine the best extraction solvent and temperature to obtain fermented rice by-products extracts with maximum cosmeceutical activities due to the varying results from this study. It was possible to infer that the choice of extraction solvent should be done depending

Table 2. Organic acid content of fermented broken rice and rice bran extracts

\begin{tabular}{|c|c|c|c|c|c|c|c|c|}
\hline \multirow{4}{*}{$\begin{array}{l}\text { Organic } \\
\text { acids }\end{array}$} & \multicolumn{8}{|c|}{ Compound content $(\mathrm{mg} / \mathrm{mL})^{*}$} \\
\hline & \multicolumn{4}{|c|}{ Fermented broken rice } & \multicolumn{4}{|c|}{ Fermented rice bran } \\
\hline & \multicolumn{2}{|c|}{ Water } & \multicolumn{2}{|c|}{$50 \% \mathrm{EtOH}$} & \multicolumn{2}{|c|}{ Water } & \multicolumn{2}{|c|}{$50 \% \mathrm{EtOH}$} \\
\hline & $30^{\circ} \mathrm{C}$ & $40^{\circ} \mathrm{C}$ & $30^{\circ} \mathrm{C}$ & $40^{\circ} \mathrm{C}$ & $30^{\circ} \mathrm{C}$ & $40^{\circ} \mathrm{C}$ & $30^{\circ} \mathrm{C}$ & $40^{\circ} \mathrm{C}$ \\
\hline Citric & $136.88 \pm 2.47^{\mathrm{a}}$ & $119.72 \pm 2.22^{b}$ & nd & nd & $0.62 \pm 0.12^{\mathrm{a}}$ & $0.56 \pm 0.04^{\mathrm{a}}$ & $0.12 \pm 0.01^{b}$ & $0.12 \pm 0.00^{\mathrm{b}}$ \\
\hline Kojic & $0.03 \pm 0.00^{\mathrm{a}}$ & $0.04 \pm 0.00^{\mathrm{a}}$ & nd & nd & $116.4 \pm 3.63^{\mathrm{a}}$ & $119.01 \pm 2.57^{\mathrm{a}}$ & nd & nd \\
\hline Ascorbic & $0.34 \pm 0.04^{\mathrm{a}}$ & $0.36 \pm 0.06^{\mathrm{a}}$ & nd & nd & nd & nd & nd & nd \\
\hline Lactic & $1.17 \pm 0.13^{\mathrm{a}}$ & $1.23 \pm 0.09^{\mathrm{a}}$ & nd & nd & $0.71 \pm 0.06^{\mathrm{a}}$ & $0.55 \pm 0.03^{\mathrm{a}}$ & nd & nd \\
\hline
\end{tabular}

Values are expressed as mean \pm SD. Values with the same superscript within the row are not significantly different $(\mathrm{p}>0.05)$. nd $=$ not detected. 
on the final application. 50\% ethanol solvent was more effective to be used for enhancing the anti-pigmentation while water was more suitable to be used for enhancing the anti-ageing function. Further studies involving other extraction condition factors such as extraction time and solvent to solid ratio or statistical optimization applications may be beneficial to thoroughly explore the cosmeceutical potentials of these extracts. To the best of our knowledge, this is the first study to demonstrate the cosmeceutical-related activities of extracts from fermented rice by-products in different extraction conditions. The data from this study confirmed an attractive array of skin-related biological activities of $A$. oryzae fermented broken rice and rice bran extracts promising them to be developed as a cosmetic ingredient for skin whitening and anti-ageing products.

\section{Acknowledgement}

This work was supported by the Malaysian Agricultural Research and Development Institute (MARDI) under the $11^{\text {th }}$ Malaysia Plan.

\section{References}

Abd Ghani, A., Jamaluddin, A., Abd Razak, D.L., Abd Rashid, N.Y. and Abd Manan, M. (2018). Study on the cosmeceutical activities and bioactive compounds of rice bran fermented with Amylomyces rouxii. International Journal of Pharma and Bio Sciences, 9(Special Issue - "International Scientific Event Symposium"), 118-124.

Abd. Razak, D.L., Abd.Rashid, N.Y., Jamaluddin, A., Abd. Ghani, A., Mansor, A. and Abdul Manan, M. (2019). Brewer's rice - A potential substrate for cosmeceutical bio-ingredient production by solid state fermentation using Aspergillus oryzae. Malaysian Journal of Microbiology, 15(4), 160-166. https://doi.org/10.21161/mjm.191541

Abd. Razak, D.L., Jamaluddin, A., Abd.Rashid, N.Y., Abd. Ghani, A. and Abdul Manan, M. (2019). Assessment of fermented broken rice extracts for their potential as functional ingredients in cosmeceutical products. Annals of Agricultural Sciences, 64(2), 176-182. https://doi.org/10.1016/ j.aoas.2019.11.003

Alam, N., Yoon, K.N., Lee, J.S., Cho, H.J. and Lee, T.S. (2012). Consequence of the antioxidant activities and tyrosinase inhibitory effects of various extracts from the fruiting bodies of Pleurotus ferulae. Saudi Journal of Biological Sciences, 19(1), 111-118. https://doi.org/10.1016/j.sjbs.2011.11.004

Alsaheb, R.A.A., Aladdin, A., Othman, N.Z., Malek, R.A., Leng, O.M., Aziz, R. and Enshasy, H.A.E.
(2015). Lactic acid applications in pharmaceutical and cosmeceutical industries. Journal of Chemical and Pharmaceutical Research, 7(10), 729-735.

Brandt, F.S., Cazzaniga, A. and Hann, M. (2011). Cosmeceuticals: current trends and market analysis. Seminars in Cutaneous Medicine and Surgery, 30(3), 141-143. https://doi.org/10.1016/j.sder.2011.05.006

Cho, E.A., Cho, E.H., Choi, S.J., Park, K.H., Kim, S.Y., Jeong, Y.J., Ku, C.S., Ha, B.J., Jang, D.I. and Chae, H.J. (2011). Screening of anti-wrinkle resource from herbal medicinal extracts and stability test of its cosmetic products. Korean Journal of Medicinal Crop Science, 19(2), 126-135. https:// doi.org/10.7783/KJMCS.2011.19.2.126

Ciganovic, P., Jakimiuk, K., Tomczyk, M. and Zovko Koncic, M. (2019). Glycerolic licorice extracts as active cosmeceutical ingredients: Extraction optimization, chemical characterization and biological activity. Antioxidants, 8(10), 445. https:// doi.org/10.3390/antiox8100445

Cui, H.X., Duan, F.F., Jia, S.S., Cheng, F.R. and Yuan, K. (2018). Antioxidant and tyrosinase inhibitory activities of seed oils from Torreya grandis Fort. ex Lindl. BioMed Research International, 2018, 5314320. https://doi.org/10.1155/2018/5314320

Dey, T.B. and Kuhad, R.C. (2014). Enhanced production and extraction of phenolic compounds from wheat by solid-state fermentation with Rhizopus oryzae RCK2012. Biotechnology Reports, 4, 120-127. https://doi.org/10.1016/j.btre.2014.09.006

Jamaluddin, A., Rashid, N.Y.A., Razak, D.L.A., Sharifudin, S.A. and Long, K. (2014). Effect of fungal fermentation on tyrosinase and elastase inhibition activity in rice bran. Agriculture and Agriculture Science Procedia, 2, 252-256. https:// doi.org/10.1016/j.aaspro.2014.11.036

Kornhauser, A., Coelho, S.G. and Hearing, V.J. (2010). Applications of hydroxy acids: classification, mechanisms and photoactivity. Clinical, Cosmetic and Investigational Dermatology, 3, 135-142. https://doi.org/10.2147/CCID.S9042

Kumar, K.S., Vani, M.G., Wang, S.Y., Liao, J.W., Hsu, L.S., Yang, H.L. and Hseu, Y.C. (2013). In vitro and in vivo studies disclosed the depigmenting effects of gallic acid: A novel skin lightening agent for hyperpigmentary skin diseases. Biofactors, 39(3), 259-270. https://doi.org/10.1002/biof.1064

López-Perea, P., Guzmán-Ortiz, F.A., Román-Gutiérrez, A.D., Castro-Rosas, J., Gómez-Aldapa, C.A., Rodríguez-Marín, M.L., Falfan-Cortes, R.N., Gonzales-Olivares, LG. and Torruco-Uco, J.G. (2019). Bioactive compounds and antioxidant 
activity of wheat bran and barley husk in the extracts with different polarity. International Journal of Food Properties, 22(1), 646-658. https:// doi.org/10.1080/10942912.2019.1600543

Ministry of Agriculture (MOA). (2017). Agrifood statistics 2017. Retrieved on March 2, 2020 from MOA Website: https://www.moa.gov.my/ documents/20182/29034/

Perangkaan+Agromakanan+2017-ilovepdfcompressed.pdf/14f6dd00-f2a1-414b-98a3251ef670d7fc

Saeedi, M., Eslamifar, M. and Khezri, K. (2019). Kojic acid applications in cosmetic and pharmaceutical preparations. Biomedicine and Pharmacotherapy, 110, 582-593. https://doi.org/10.1016/ j.biopha.2018.12.006

Schmidt, C.G., Goncalves, L.M., Prietto, L., Hackbart, H.S. and Furlong, E.B. (2014). Antioxidant activity and enzyme inhibition of phenolic acids from fermented rice bran with fungus Rizhopus oryzae. Food Chemistry, 146, 371-377. https:// doi.org/10.1016/j.foodchem.2013.09.101

Shi, J., Yu, J., Pohorly, J., Young, J.C., Bryan, M. and $\mathrm{Wu}, \mathrm{Y}$. (2003). Optimization of the extraction pf polyphenols from grape seed meal by aqueous ethanol solution. Journal of Food, Agriculture and Environment, 1(2), 42-47.

Song, S.Y., Song, S.H., Bae, M.S. and Cho, S.S. (2019). Phytochemical constituents and the evaluation biological effect of Cinnamomum yabunikkei $\mathrm{H}$. Ohba leaf. Molecules, 24(1), 81. https:// doi.org/10.3390/molecules24010081

Spigno, G., Tramelli, L. and Faveri, D.M.D. (2007). Effects of extraction time, temperature and solvent on concentration and antioxidant activity of grape marc phenolics. Journal of Food Engineering, 81(1), 200-208. https://doi.org/10.1016/ j.jfoodeng.2006.10.021

Su, T.R., Lin, J.J., Tsai, C.C., Huang, T.K., Yang, Z.Y., Wu, M.O., Zheng, Y.Q., Su, C.C.and Wu, Y.J. (2013). Inhibition of melanogenesis by gallic acid: possible involvement of the PI3K/Akt, MEK/ERK and $\mathrm{Wnt} / \beta$-catenin signaling pathways in B16F10 cells. International Journal of Molecular Sciences, 14(10), 20443-20458. https://doi.org/10.3390/ ijms141020443

Taofiq, O., Heleno, S.A., Calhelha, R.C., Alves, M.J., Barros, L., Barreiro, M.F., Gonzales-Paramas A.M. and Ferreira, I.C. (2016). Development of mushroom -based cosmeceutical formulations with antiinflammatory, anti-tyrosinase, antioxidant and antibacterial properties. Molecules, 21(10), 1372. https://doi.org/10.3390/molecules21101372
Thangboonjit, W., Pluemsamran, T. and Panich, U. (2014). Comparative evaluation of antityrosinase and antioxidant activities of dietary phenolics and their activities in melanoma cells exposed to UVA. Siriraj Medical Journal, 66(1), 5-10.

Venkatesan, T., Choi, Y.W. and Kim, Y.K. (2019). Impact of different extraction solvents on phenolic content and antioxidant potential of Pinus densiflora bark extract. BioMed Research International, 2019,3520675 . https:// doi.org/10.1155/2019/3520675

Wang, G.H., Chen, C.Y., Lin, C.P., Huang, C.L., Lin, C.H., Cheng, C.Y. and Chung, Y.C. (2016). Tyrosinase inhibitory and antioxidant activities of three Bifidobacterium bifidum-fermented herb extracts. Industrial Crops and Products, 89, 376382. https://doi.org/10.1016/j.indcrop.2016.05.037

Wu, L., Chen, C., Cheng, C., Dai, H., Ai, Y., Lin, C. and Chung, Y. (2018). Evaluation of tyrosinase inhibitory, antioxidant, antimicrobial and antiaging activities of Magnolia officinalis extracts after Aspergillus niger fermentation. BioMed Research International 2018, 5201786. https:// doi.org/10.1155/2018/5201786

Zaidi, K.U., Ali, A.S., Ali, S.A. and Naaz, I. (2014). Microbial tyrosinases: promising enzymes for pharmaceutical, food bioprocessing and environmental industry. Biochemistry Research International, 2014, $854687 . \quad \mathrm{https} / /$ doi.org/10.1155/2014/854687 